\title{
A chemical analysis of the salt content of sandwiches purchased from independent outlets
}

\author{
E.S. Watts ${ }^{1}$, I.G. Davies ${ }^{2}$, J.K. Sinclair ${ }^{1}$ and S.A. Dillon ${ }^{1}$ \\ ${ }^{1}$ Division of Sport Exercise and Nutritional Sciences, School of Sport, Tourism and The Outdoors, \\ University of Central Lancashire, Preston, PRI 2HE, UK and ${ }^{2}$ Faculty of Education, Health and Community, \\ IM Marsh Campus, Liverpool John Moores University, Liverpool, L17 6BD, UK
}

In recent years there has been an increase in eating away from home and sandwiches are popular choices which are often viewed as the healthy option ${ }^{1-2}$. However, foods eaten away from home are characterised as having a high salt content and are generally nutritionally inadequate ${ }^{3-6}$. Diet is widely recognized as a modifiable determinant of health and considering the prevailing problem of non-communicable disease ${ }^{7}$ the nutritional quality of food served from independent sandwich outlets is of considerable public health concern. Therefore the present pilot study investigated the salt content of sandwiches purchased from six independent outlets in the UK. A convenience sample of three popular categories of sandwiches (cheese, tuna, and chicken-tikka) were analysed and the results compared against national guidelines. Samples $(\mathrm{n}=36)$ were analysed for sodium by atomic absorption spectrometry and values were converted to salt using a standard conversion factor $(2 \cdot 54)^{8}$. The calculated salt content of sandwiches (per portion as consumed) from independent outlets was high (Cheese: $3.00 \pm 0.97 \mathrm{~g}$, Chicken: $2.88 \pm 0.74 \mathrm{~g}$, Tuna: $2.78 \pm 0.46 \mathrm{~g}$ ). In comparison to current guidelines for intake of salt per meal for an adult $(1.8 \mathrm{~g})$ these levels equate to over-consumption by an average of $160 \%$. Regular consumption of sandwiches purchased from independent outlets, particularly in combination with other high salt foods, may contribute to the development of hypertension. Given the popularity of commercially prepared sandwiches, addressing the salt content would have a major public health benefit.

1. Tangari A, Burton S, Howlett E, Cho Y, Thyroff A. (2010) Weighing in on fast food consumption: the effects of meal and calorie disclosures on consumer fast food evaluations. $J$ Consumer Affairs 44(3), 431-462.

2. Hwang J, Cranage D. (2010) Customer health perceptions of selected fast-food restaurants according to their nutritional knowledge and health consciousness. J Foodservice Business Res 13(2), 68-84.

3. Stender S, Dyerberg J, Astrup A. (2007) Fast food: unfriendly and unhealthy. Int J Obesity 31(6), 887-890.

4. Jaworowska A, Blackham T, Stevenson L, Davies IG. (2012) Determination of salt content in hot takeaway meals in the United Kingdom. Appetite 59(2), 517-522.

5. Nielsen S, Popkin B. (2003) Patterns and trends in food portion sizes, 1977-1998. JAMA 289(4), 450-453.

6. Prentice A, Jebb S. Fast foods, energy density and obesity: a possible mechanistic link. Obesity Rev 2003; 4(4), $187-194$.

7. World Health Organization. (2010) Global status report on noncommunicable diseases. WHO.

8. Food Standard Agency. 2017 UK salt reduction targets. http://www.food.gov.uk/scotland/scotnut/salt/saltreduction (accessed 4th May 2014). 